\title{
AN INTEGRATED INTELLIGENT SYSTEM FOR CONSTRUCTION INDUSTRY: A CASE STUDY OF RAISED FLOOR MATERIAL
}

\author{
Abdullah Cemil ILCE ${ }^{1}$, Kadir OZKAYA ${ }^{2}$ \\ ${ }^{1}$ Department of Industrial Engineering, Faculty of Engineering and Architecture, \\ Abant Izzet Baysal University, Golkoy Yerleskesi Merkez/Bolu 14280 Turkey \\ ${ }^{2}$ Department of Materials and Materials Processing Technology, Denizli Vocational School of Technical \\ Sciences, Pamukkale University, Camlaraltı Mah. Fakülte Cad. No:30, Kınıkl 20160, Denizli, Turkey
}

Received 21 April 2016; accepted 21 May 2017

\begin{abstract}
This paper aims to introduce a quantitative method to builders for the most appropriate material selections based on multiple attributes and integrate decision group member opinions throughout bidding process. In this respect, a new model used together with the Analytic Hierarchy Process (AHP) and fuzzy Multi-Objective Optimization on the Basis of Ratio Analysis (MOORA), multi-criteria decision methods are proposed. In a real decision process, there are many uncertainties and ambiguities. In fact decision makers cannot always provide practical guidelines and especially precise judgments due to time limitations. The intelligent model proposed demonstrates that the AHP and fuzzy MOORA approach can not only be used easily to imitate the decision duration in the material selection but also the results obtained from this work provide contractors valuable insight into the material selection problem. At the same time, the quantitative analysis method based on the appropriately raised floor materials along the bidding process enables the builders to use their restricted resources more expeditiously and enhances considerably the possibility of winning agreement, as one of the most striking points deduced from the present study. In short, the model with AHP and fuzzy MOORA approaches can assist the builders to improve resolutions for the bidding.
\end{abstract}

Keywords: material selection, the cost of purchasing, intelligent selection system, reduce workload, AHP, fuzzy MOORA.

JEL Classification: C44, C81, C82, D81, L68.

\section{Introduction}

Firms must exhibit the high capability to evaluate diverse bidding states successfully in extremely competitive construction market so that they keep up with today's conditions. In case of the tender invitation, the first step to be considered by the companies is whether to bid or not. However, contractor's decision is seriously affected by various factors and influences as

\footnotetext{
${ }^{\star}$ Corresponding author. E-mail: cemil.ilce@gmail.com
} 
a consequence of reliance to certain project and the macro periphery. Thus, it is difficult to make the crucial decision in a short time by the management team.

One of the difficult decisions is that the contractors choose the materials used in all the constructions. Raised floor providing an elevated structural floor above a solid substrate can be expressed as a manufacturing method applied on top of existing flooring and new flooring with panels placed on point bases with adjustable heights. All kinds of installations as regards the electricity and computer cables can be conveyed to desired points by passing them through the empty spaces under the raised flooring. Furthermore, another advantage is that the panels produced by raised flooring can be removed easily. Hence, to be more precise, the panel enables effortlessly to eliminate/fix the installation defects; or to make changes in the system in case of necessity (Ilce 2007).

The raised floor materials with their intrinsic flexible and changeable properties have been widely used in present-day offices. However, the selection of raised floor panels for office decoration is known as a commonly difficult decision-making problem. The experts should be extremely knowledgeable about physical, technical, aesthetic, economic and adaptation to the environment properties of the materials. At the same time, it is possible to compare the products of different companies according to above given criteria.

Present study aims to select the most appropriate supplier company for decoration by using the AHP and fuzzy MOORA methods. Here, it is necessary to underline that the latter approach exhibits superior features to the traditional methods in terms of fixing some inherent problems in the other models. Thus, the model of fuzzy MOORA gives more attractive/reliable results compare to others that is the main reason why we prefer this model throughout the multi-criteria decision approach conducted in this work.

The raised floor panels are obtained from the supplier companies and are tested in terms of compliance with the standards for technical and physical properties. The most suitable raised floor panel selection is made from the data obtained in the tests. The properties that should be provided in the standards can be used as the evaluation criteria of the materials. During the evaluation of the materials, the physical, technical and price criteria are considered seriously, and the AHP and fuzzy MOORA analyses are conducted on the real values of secondary criteria connected to the primary criteria.

\section{Literature review}

In any case, the decision-making mechanism is one of the most important activities in the business world (Dağdeviren, Eren 2001). Whenever a company engages in the tender invitation, the scientific methods should be at the forefront of decision-making process to ensure making better decisions (Zahedi 1987; Vargas 1990).

The criteria used for making decisions can display the different needs of companies (Kahraman et al. 2003). Generally, the most commonly considered criteria include quality, delivery, price/cost, manufacture capability, labor-intensity, administration, technology, researchdevelopment, investment, flexibility, respect, relations, risk, security and environment (Ho et al. 2010). In the literature, the criteria that should be taken into account while choosing supplier are classified into three main groups: (I) financial, (II) technical and (III) operations success (Arbel, Orgler 1990; Zviran 1993; Ghodsypour, Brien 1998; Tam, Tummala 2001). 
Additionally, Multi-Objective Optimization on the Basis of Ratio Analysis (MOORA) methods and other multi-criteria decision methods are used in several studies conducted for selection of companies or products with some scientific methods. Such methods are applied on various subjects regarding the cutting-machine selection, ERP system selection, optimal network system selection, personnel selection, supply chain strategy selection, selection of the best intelligent manufacturing system and ranking different farming operations efficiency, alliance planning and partners selection and industrial engineering sector selection (Balezentis 2011; Karande, Chakraborty 2012; Archana, Sujatha 2012; Balezentis et al. 2012; Dey et al. 2012; Mandal, Sarkar 2012; Vatansever, Kazançoğlu 2014; Akhavan et al. 2015; Akkaya et al. 2015).

\subsection{Analytic hierarchy process (AHP)}

The analytic hierarchy process (AHP) is a structured technique for organizing and analyzing complex decisions, based on mathematics and psychology. It was developed by Thomas L. Saaty in the 1970s and has been extensively studied and refined since then. It is one of the best and most widely used MCDM approaches. As well known, AHP is an approach for decision making that involves structuring multiple choice criteria into a hierarchy, evaluating the relative significance of criteria, comparing alternatives for every criterion and determining an overall ranking of the alternatives (Douligeris, Pereira 1994). In this respect, the AHP approach helps to capture both subjective and objective evaluation measures, providing a useful mechanism to check the consistency of the assessment measures and alternatives proposed by the team thus reducing bias in decision making (Lai et al. 1999). In recent years, the literature for AHP has widely been used in solving many complicated decision-making problems (Ho 2008; Deng et al. 2014; Xu et al. 2013; Uyan 2013; Mansor et al. 2013; Oztaysi 2014; Sivakumar et al. 2015).

The application steps of the AHP method are as follows (Saaty 1990, 2008):

- The first step: The decision hierarchy is formed based on the objective, by which the criteria affected by the selection are determined carefully. Subsequently, the potential alternatives are constituted by taking into account the criteria. In conclusion, a hierarchical structure is formed for the decision mechanism.

- The second step: Pairwise comparison $(n \mathrm{x} n)$ decision matrixes (A) are formed as shown in the Eq. (1) statement to compare both the alternatives on the foundation of each criterion and the criteria with each other. Value of the matrix elements must have a greater than zero $\left(a_{i j}>0, i, j=1,2, \ldots, n\right)$. The components (since $\left.I=j\right)$ remaining above the diagonal of the comparison matrix obtain the value of $1\left(a_{i i}=1\right)$. The pairwise criteria comparisons are made for the values remaining above the diagonal, which is 1 for all the values of the comparison matrix. However, the $a_{j i}=1 / a_{i j}$ equation is used for the components remaining below the diagonal. The 1-9 significance scales proposed by Saaty (1990) for the formation of these matrixes are given in Table 1 in detail.

- The third step: The priority vectors are calculated starting from the pairwise comparisons by means of Eq. (2). Hence, the W column vectors (known as priority vectors) relating to the significance weights of the criteria are calculated. 


$$
\begin{aligned}
A=\left(a_{i j}\right)_{n x n} & =\left(\begin{array}{cccc}
a_{11} & a_{12} & \cdots & a_{1 n} \\
a_{21} & a_{22} & \cdots & a_{2 n} \\
\cdots & \cdots & \cdots & \cdots \\
\cdots & \cdots & \cdots & \cdots \\
\cdots & \cdots & \cdots & \cdots \\
a_{n 1} & a_{n 2} & \cdots & a_{n n}
\end{array}\right) ; \\
w_{i} & =\frac{\sum_{j=1}^{n} a_{i j}}{n} .
\end{aligned}
$$

Table 1. Significance scale and its definition

\begin{tabular}{|c|l|}
\hline Importance & \multicolumn{1}{|c|}{ Definition } \\
\hline 1 & Equal significance both element \\
\hline 3 & Weak significance one element over another \\
\hline 5 & Essential or strong significance one element over another \\
\hline 7 & Demonstrated significance one element over another \\
\hline 9 & Absolute significance one element over another \\
\hline $2,4,6,8$ & Intermediate values between two adjacent judgments \\
\hline
\end{tabular}

- The fourth step: It is composed of the calculation of consistency ratios (Eq. (3)). The core vector method can be used to enable measuring the consistency in the comparisons made by the decision-making group. In this method, it is necessary to calculate the Consistency Ratio (CR). If the CR value is lower than 0.10, then the comparisons made by decision-makers is deemed consistent. For the CR value equal or above 0.10 , the comparisons are inconsistent; or there is a serious calculation error. This is attributed to the fact that the comparisons need to be re-examined clearly. The CR value is the ratio between the Consistency Index (CI) and the Random Index (RI) value.

$$
C R=\frac{C I}{R I}
$$

The Consistency Index is also calculated by the following relation Eq. (4):

$$
C I=\frac{\lambda_{\max }-n}{n-1} \text {. }
$$

In the equation, $\lambda_{\max }$ is the largest eigenvalue whereas $n$ specifies the number of criteria. The A vector is multiplied with the $\mathrm{w}$ vector for calculation of the $\lambda_{\max }$. Consequently, $\left(E_{i}\right)$ values are formed by dividing the $w_{i}$ values of the $\mathrm{D}$ column vector elements obtained. The parameter of $\lambda_{\max }$ is obtained from the ratio of the $E_{i}$ values to the total number of criteria (Eq. (5)-(6)). 


$$
\begin{gathered}
D=\left(\begin{array}{cccc}
a_{11} & a_{12} & \cdots & a_{1 n} \\
a_{21} & a_{22} & \cdots & a_{2 n} \\
\cdots & \cdots & \cdots & \cdots \\
\cdots & \cdots & \cdots & \cdots \\
\cdots & \cdots & \cdots & \cdots \\
a_{n 1} & a_{n 2} & \cdots & a_{n n}
\end{array}\right) \times\left(\begin{array}{c}
w_{1} \\
w_{2} \\
\cdots \\
\cdots \\
\cdots \\
w_{n}
\end{array}\right), E_{i}=\frac{d_{i}}{w_{i}} \quad(i=1,2,3, \ldots, n) \\
\lambda_{\max }=\frac{\sum_{i=1}^{n} E_{i}}{n} .
\end{gathered}
$$

The average consistency values are calculated from the matrixes formed randomly for the matrix of every $\mathrm{n}$ dimension, which is called as the Random Index (RI). The random index values connected to the number of criteria are given in Table 2 (Saaty 1990). In the procedures performed until this step, the weights of the criteria which influence the solution of the decision-making problem could be determined easily. After that step, just as the analysis of alternatives are made by using the comparison matrixes (in the presence of different decision-making methods other than the AHP), the criteria weights can provide the inputs.

Table 2. Random Index Values

\begin{tabular}{|c|c|c|c|c|c|c|c|c|c|}
\hline$n$ & 1 & 2 & 3 & 4 & 5 & 6 & 7 & 8 & 9 \\
\hline $\mathrm{RI}$ & 0 & 0 & 0.58 & 0.9 & 1.12 & 1.24 & 1.32 & 1.41 & 1.45 \\
\hline
\end{tabular}

- The fifth step: The decision alternatives, by taking into account all the criteria separately, are given for the pairwise comparisons in the scope of the criteria given above. Matrixes are formed up to the number of $n$ (criteria number) and the alternative number is shown with " $m$ ", thus it is necessary for the dimension of every comparison matrix to form $\mathrm{m} \mathrm{x} \mathrm{m}$.

- The last step: The calculation of the weighted points is exerted for the alternatives. The analysis of alternatives presents that the $\mathrm{n}$ pieces $\mathrm{m} \times 1$ dimensioned column vector constitutes the $\mathrm{m} \times \mathrm{n}$ dimensioned choice matrix as a result of the criteria comparisons. A new column vector is obtained by being multiplied with the w column vector in the matrix. Every element of this vector shows the points of the decision alternatives. The total point of 1 within the values emerged displays the most appropriate alternative as a result of the highest points (significance).

\subsection{Fuzzy MOORA}

Multi-objective optimization on the basis of ratio analysis (MOORA) is also known as the multi-criteria or multi-attribute optimization. It is outlined as the process of simultaneously optimizing two or more contradictory attributes subjected to some constraints (Chakraborty 2010; Karande, Chakraborty 2012). Similar to other multi- criteria decision making (MCDM) tool, MOORA method firstly proposed by Brauers (2004) and Brauers and Zavadskas (2006) is used to priorities the alternatives on the basis of several criteria or objectives. 
There is a table corresponding to the main differences between several MCDM methods. Table 3 also reveals that MOORA is far stronger than the traditional MCDM methods in many aspects (Brauers, Zavadskas 2012).

According to Table 3, it is challenging to decide the right method to be used. For that reason, it is decided to use two methods by combining them instead of a single method by analyzing the similar studies in the literature. AHP method is the one mostly used in determining criteria weights by researchers (Chang, Tsai 2016; Wang et al. 2015; Pourahmad et al. 2015; Ecer 2014; Zolfani et al. 2012; Kaya, Kahraman 2011). Decision makers focus on smaller decision clusters by dividing the problem into several levels by this method. Capability of processing quantitative and qualitative methods together and very good level of calculation ability are the advantageous aspects. On the other hand, MOORA method is a multi-criteria decision making method distinguished in academic studies thanks to its reliability, simplicity and time of calculation. For this reason; AHP and MOORA methods are combined and used together in this study. By this way, it is suggested to conduct an evaluation that enables to make a better calculation on diverse data, is a more reliable and makes a shorter term calculation with respect to material selection in the bidding process that requires to perform rapid and correct analysis.

Table 3. Comparative performance of some MODM methods.

\begin{tabular}{|c|c|c|c|c|c|}
\hline $\begin{array}{c}\text { MCDM } \\
\text { method }\end{array}$ & $\begin{array}{c}\text { Computational } \\
\text { time }\end{array}$ & Simplicity & $\begin{array}{c}\text { Mathematical } \\
\text { calculations }\end{array}$ & Stability & $\begin{array}{c}\text { Information } \\
\text { type }\end{array}$ \\
\hline Moora & Very low & Very simple & Minimum & Good & Quantitative \\
\hline Ahp & Very high & Very critical & Maximum & Poor & Mixed \\
\hline Topsis & Moderate & Moderately critical & Moderate & Medium & Quantitative \\
\hline Vikor & Less & Simple & Moderate & Medium & Quantitative \\
\hline Electre & High & Moderately critical & Moderate & Medium & Mixed \\
\hline Promethee & High & Moderately critical & Moderate & Medium & Mixed \\
\hline
\end{tabular}

In MOORA method, the overall performance of all the alternatives is adapted as the difference among sums of its normalized performances for useful and non-useful criteria by using the Eq. (7).

$$
y_{i}^{*}=\sum_{i=1}^{g} X_{i j}^{*}-\sum_{i=g+1}^{n} X_{i j}^{*},
$$

where $x_{i j}{ }^{*}$ as a normalized reply of alternative $\mathrm{j}$ on objective $i ; i=1,2, \ldots, \mathrm{g}$ as the goals to be maximized; $i=g+1, g+2, \ldots, n$ as the goals to be minimized; $j=1,2, \ldots, m$ as the alternatives; and $y_{i}^{*}$ as the all ranking index of alternative $j$. 
When the precedence weights are considered to give relative significance of one criterion over the other, Eq. (8) can be rewritten as:

$$
y_{i}=\sum_{i=1}^{g} w_{j} X_{i j}^{*}-\sum_{i=g+1}^{n} w_{j} X_{i j}^{*} \quad(j=1,2, \ldots, n),
$$

where $w_{j}$ is the weight of $\mathrm{j}$ criterion to be identified by AHP or entropy technique. The best alternative shows the highest $y_{i}$ value while the lowest $y_{i}$ value is associated with the worst alternative.

This paper uses triangular fuzzy number for fuzzy MOORA. The main goal of the use of a triangular fuzzy number is to enable decision-makers to make calculations easily and intuitively. In addition, the model using the triangular fuzzy numbers has approved to be a powerful way for formulation of the decision making problems where the knowledge existent is subjective and blurred (Zimmerman 1996; Chang, Yeh 2002; Kahraman et al. 2004; Chang et al. 2007; Dağdeviren et al. 2009). In applications, the triangular form of the membership function is most often used for representing the fuzzy numbers (Karsak, Tolga 2001; Kahraman et al. 2004; Ding, Liang 2005; Chen et al. 2006; Xu, Chen 2007; Dağdeviren et al. 2009). Below some basic important definitions of fuzzy sets are given (Zadeh 1965; Zimmerman 1996; Cheng 1997; Raj, Kumar 1999; Wang, Chang 2007; Önüt, Soner 2008; Dağdeviren et al. 2009)

- Definition 1: A fuzzy set $\tilde{A}$ in a universe of discourse $\mathrm{X}$ is characterized by a membership function $\mu_{\tilde{A}}(\mathrm{x})$ which partners with each element $\mathrm{x}$ in $\mathrm{X}$ an actual number in the interval $[0,1]$. The function value $\mu_{\tilde{A}}(\mathrm{x})$ is termed as the grade of membership of $x$ in $\tilde{A}$.

- Definition 2: A triangular fuzzy number $\tilde{A}$ can be diverse by a trio (a1, a2, a3) shown in Figure 1. The membership function $\mu_{\tilde{a}}(\mathrm{x})$ is outlined.

$$
\mu_{\tilde{a}}(x)=\left\{\begin{array}{cc}
0, & x<a_{1} \\
\frac{x-a_{1}}{a_{2}-a_{1}}, & a_{1} \leq x \leq a_{2} \\
\frac{a_{3}-x}{a_{3}-a_{2}}, & a_{2} \leq x \leq a_{3} \\
0 & x>a_{3}
\end{array} .\right.
$$

Let $\tilde{a}$ and $\tilde{b}$ be two triangular fuzzy numbers parameterized by the triplet (a1, a2, a3) and (b1, b2, b3), respectively, then the operational laws of these two triangular fuzzy numbers are as follows:

$$
\begin{aligned}
& \tilde{a}(+) \tilde{b}=\left(a_{1}, a_{2}, a_{3}\right)(+)\left(b_{1}, b_{2}, b_{3}\right)=\left(a_{1}+b_{1}, a_{2}+b_{2}, a_{3}+b_{3}\right) \\
& \tilde{a}(-) \tilde{b}=\left(a_{1}, a_{2}, a_{3}\right)(-)\left(b_{1}, b_{2}, b_{3}\right)=\left(a_{1}-b_{3}, a_{2}-b_{2}, a_{3}-b_{1}\right) ; \\
& \tilde{a}(\times) \tilde{b}=\left(a_{1}, a_{2}, a_{3}\right)(\times)\left(b_{1}, b_{2}, b_{3}\right)=\left(a_{1} \times b_{1}, a_{2} \times b_{2}, a_{3} \times b_{3}\right) \\
& \tilde{a}(\div) \tilde{b}=\left(a_{1}, a_{2}, a_{3}\right)(\div)\left(b_{1}, b_{2}, b_{3}\right)=\left(a_{1} \div b_{3}, a_{2} \div b_{2}, a_{3} \div b_{1}\right) .
\end{aligned}
$$




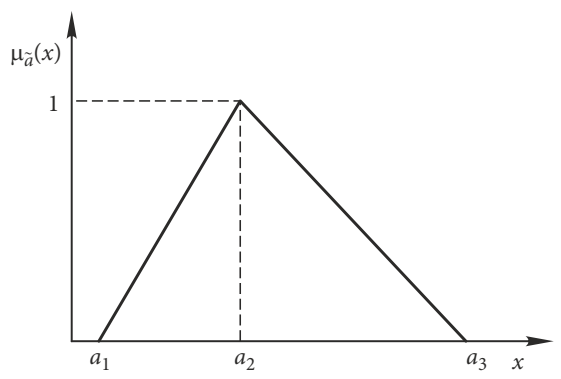

Figure 1. A triangular fuzzy membership

- Definition 3: A linguistic variable is a variable that is expressed with linguistic terms (Zadeh 1975; Chen 2000; Dağdeviren et al. 2009). The concept of linguistic variable is very useful for addressing the situations which are too complicated or too ill-defined to be reasonably identified in conventional quantitative expressions (Zadeh 1975; Chen 2000; Dağdeviren et al. 2009). For example, the values of "weight" as a linguistic variable are very low, low, medium, high, very high, etc. Fuzzy numbers may also represent these linguistic values.

- Definition 4. Supposing $\tilde{a}$ (a1, a2, a3) and $\tilde{b}$ (b1, b2, b3) are two triangular fuzzy numbers, then the vertex method is defined to calculate the distance between them.

$$
d(\tilde{a}, \tilde{b})=\sqrt{\frac{1}{3}\left[\left(a_{1}-b_{1}\right)^{2}+\left(a_{2}-b_{2}\right)^{2}+\left(a_{3}-b_{3}\right)^{2}\right] .}
$$

- Definition 5. Considering the diverse significance values of each criterion, the weighted normalized fuzzy-choice matrix is built as follows.

$$
\widetilde{V}=\left[\tilde{v}_{i j}\right]_{n \times j}, i=1,2 \ldots . n, j=1,2 \ldots . J,
$$

where $\tilde{v}_{i j}=x_{i j} \times w_{i}$ A set of performance ratings of $A_{j}(j=1,2, \ldots, J)$ with respect to criteria $C_{i}(i=1,2, \ldots, n)$ is called $\tilde{X}=\left\{\tilde{x}_{i j}, i=1,2 \ldots . ., J=1,2, \ldots . . J\right\}$. A set of significance weights of each criterion $w_{i}(i=1,2, \ldots, n)$.

According to shortly abstracted fuzzy theory hereinabove, the fuzzy MOORA phases may be defined as follows (Balezentis 2011; Karande, Chakraborty 2012; Archana, Sujatha 2012; Dey et al. 2012; Stanujkic 2013; Vatansever, Kazançoğlu 2014):

- $\quad$ Step 1: Based on the precious opinions of the expert team members, the fuzzy choice matrix can be developed and hence all the criteria are measured using the triangular membership function.

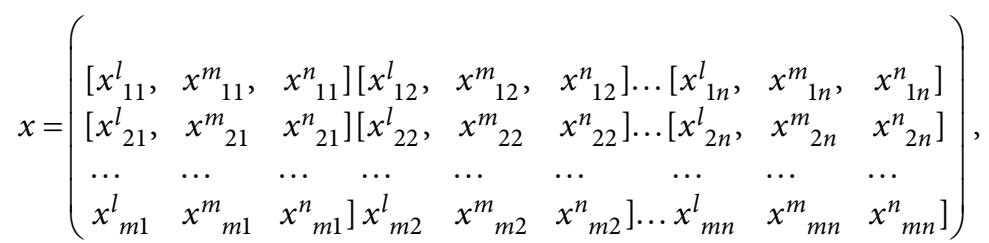

where $x_{i j}{ }^{l}, x_{i j}{ }^{m}$ and $x_{i j}{ }^{n}$ indicate the lower, middle and upper values of a triangular membership function $i^{\text {th }}$ alternative with respect to $j^{\text {th }}$ criterion. 
- Step 2: Normalize the fuzzy choice matrix utilization vector normalization technique. The following calculations are approved for this purpose.

$$
\begin{aligned}
& r_{i j}^{l}=\frac{x_{i j}^{l}}{\sqrt{\sum_{i=1}^{m}\left[\left(x_{i j}^{l}\right)^{2}+\left(x_{i j}^{m}\right)^{2}+\left(x_{i j}^{n}\right)^{2}\right]}} ; \\
& r_{i j}^{m}=\frac{x_{i j}^{m}}{\sqrt{\sum_{i=1}^{m}\left[\left(x_{i j}^{l}\right)^{2}+\left(x_{i j}^{m}\right)^{2}+\left(x_{i j}^{n}\right)^{2}\right]}} ; \\
& r_{i j}^{n}=\frac{x_{i j}^{n}}{\sqrt{\sum_{i=1}^{m}\left[\left(x_{i j}^{l}\right)^{2}+\left(x_{i j}^{m}\right)^{2}+\left(x_{i j}^{n}\right)^{2}\right]}}
\end{aligned}
$$

- Step 3: Conclude the weighted normalized fuzzy choice matrix using the following calculations:

$$
\begin{aligned}
& v_{i j}{ }^{l}=w_{j} r_{i j}^{l} ; \\
& v_{i j}{ }^{m}=w_{j} r_{i j}^{m} ; \\
& v_{i j}{ }^{n}=w_{j} r_{i j}^{n} .
\end{aligned}
$$

Compute the total scores of useful and non- useful criteria for each alternative. For useful criteria, the general scores of an alternative for lower, middle and upper values belonging to the triangular membership function are calculated as follows:

$$
\begin{aligned}
s_{i}^{+l} & =\sum_{j=1}^{n} v_{i j}^{l} \mid \mathrm{j} \in J^{\max } ; \\
s_{i}^{+m} & =\sum_{j=1}^{n} v_{i j}^{m} \mid \mathrm{j} \in J^{\max } ; \\
s_{i}^{+n} & =\sum_{j=1}^{n} v_{i j}^{n} \mid \mathrm{j} \in J^{\max } .
\end{aligned}
$$

On the other hand, for non-useful criteria, the total scores of an alternative are calculated as follows,

$$
\begin{aligned}
s_{i}^{-l} & =\sum_{j=1}^{n} v_{i j}^{l} \mid \mathrm{j} \in J^{\max } ; \\
s_{i}^{-m} & =\sum_{j=1}^{n} v_{i j}^{m} \mid \mathrm{j} \in J^{\max } ; \\
s_{i}^{-n} & =\sum_{j=1}^{n} v_{i j}^{n} \mid \mathrm{j} \in J^{\max } .
\end{aligned}
$$

- Step 5: Define the whole performance index $\left(\mathrm{S}_{\mathrm{i}}\right)$ for each alternative. For this, the deactivate values of the whole ratings for useful and non-useful criteria of every alternative can be calculated with the vertex method as follows (Karande, Chakraborty 2012). 


$$
S_{i}\left(s_{i}^{+}, s_{i}^{-}\right)=\sqrt{\frac{1}{3}\left[\left(s_{i}^{+l}-s_{i}^{-l}\right)^{2}+\left(s_{i}^{+m}-s_{i}^{-m}\right)^{2}+\left(s_{i}^{+n}-s_{i}^{-n}\right)^{2}\right.} .
$$

- Step 6: Based on the falling values of the whole performance index, rank the alternatives from the best to the worst. The alternative with the highest whole performance index is acknowledged to be the most satisfactory choice (Karande, Chakraborty 2012; Vatansever, Kazançoğlu 2014).

\subsection{The proposed model}

The proposed model created for AHP and fuzzy MOORA methods for the raised floor choice practice consists of three simple phases:

- Definition of the conditions to be used in the model,

- AHP calculations,

- Assessment of the options with fuzzy MOORA and determination of the ultimate order. In the first phase, the different raised floors and their evaluation criteria are identified seriously so that the decision order is designed.

The AHP model is planned with respect to the fact that the objective comes first, criteria come second and different panels come third. In the last step, the choice hierarchy is agreed by the expert team.

In the second phase, the calculations of AHP are made. The matrices are designed to regulate the criteria weights. The experts create pair-wise comparison matrices between criteria by using the significance weights given in Table 1 in direction of their own opinions. Calculation of the geometric mean of the values obtained from singular assessments enables us to create a final pair-wise comparison matrix, being supported by the expert team. The weights of the status are calculated based on the ultimate comparison matrix. Once for all, the weights deduced from the criteria are accepted by the expert team.

At the final stage, the raised floor panel orders are identified using the fuzzy MOORA method. Linguistic values are used for the assessment of other panels in this step. The affiliation functions of the linguistic values are schematically shown in Figure 1. Likewise, the triangular fuzzy numbers concerned with the variables are shown in Table 2 . The expert team used physical and technical performance evaluations along with the realized values of raised floor panels. The panel presenting the maximum index numbers is defined as the optimum panel with respect to computations conducted by the Fuzzy MOORA approach.

\section{Case study: a numeric application of proposed model}

At this stage, the selection of raised floor for a decoration company is made with the applications specified in the method proposed because of irresolution. The selection of raised floor panel depending on only the price leads to disregarding the performance criteria. Similarly, the selection based only on the performance criteria can result in higher prices. Moreover, the excessive performance criteria bring out new problems related to which criterion plays an important role in proper material selections. In the present study, the real experimental values belonging to the criteria are used. 
The criteria to be used in the model are defined by the expert team. Two of the team members is an assistant professor in the field of material. The other is the unit supervisor of the Turkish Standards Institute. The expert team was formed meticulously for unbiased elevation.

Criteria to be considered in the choice of raised floor are defined based on the past experience of the expert team and the backgrounds of the expert team are used in designation of the 5 primary criteria.

Besides, 17 important secondary criteria are established for the raised floor choice. The primary criteria, the secondary criteria and their descriptions of significance are given in Table 4 .

After description of the primary criteria and secondary criteria, a pre-study is made with four raised floor panels. As a consequence of the pre-study, it is observed that some of the primary criteria and secondary criteria are shared for all of the panels when the decision hierarchy is established by reducing both the number of primary criteria to 3 and the number of secondary criteria to 10 . The 3 primary criteria and 10 secondary criteria given above are as follows: Physical properties (C1), density (SC1), thickness swelling (24 hour) (SC2), mechanical properties (C2), point load at the center of the panel (SC3), point load at the center of the corner (SC4), distributed load (SC5), corner veneer bonding strength (SC6), scratching resistance (SC7), wear resistance (SC8), electrical conduction resistance (SC9), cost properties (C3), material price (SC10).

After creating the choice hierarchy for the practice, the weights of the criteria to be assessed in calculation practice are calculated by operating the AHP method. At this stage, the experts are taken for the duty of making singular pairwise comparison matrix by operating the Saaty's 1-9 scale. Geometric means of the values are established to obtain the pair-wise comparison matrix which points out a strong agreement, and the outcomes drawn from the calculations relying on the pairwise comparison matrix are provided in Table 5 clearly.

It is determined that the most important criteria deduced from the comparison are technical properties (C2). Besides, it is established that the physical properties (C1) and the cost (C3) exhibits almost equal significance. Consistency ratio of the pairwise comparison matrix is, in this respect, determined as $0.008<0.1$. Hence, it is tempting to speculate that the weights accessed in the choice process are evidenced as logical.

The density and the swelling of thickness included in the physical properties as the primary criteria are considered as having equal degree of significance by the team. The weight ratio of two criteria (density and swelling of thickness) in the primary criteria are adjusted to be SC1 $=0.5$ and SC2 $=0.5$. There are 7 secondary criteria for the technical properties included in the primary criteria. The pairwise comparison matrixes are given in Table 6 . Since there is only the price sub-criterion under the cost primary criteria, the weight value for primary criteria is valid within the price sub-criterion.

In the comparison of secondary criteria, the most important criterion is determined as the distributed load-bearing property. This is followed by the point load-bearing property at the center of the panel and point load-bearing property at the center of the corner, corner veneer bonding strength, wear resistance, scratching resistance and electrical conduction resistance, respectively. The consistency ratio of the pairwise comparison matrix is calculated as $0.050<0.1$. Thus, one can be convinced rapidly that they are used in the selection process as a consequence of high extent of agreement. 
Table 4. Raised floor panel evaluation criteria and its definition

\begin{tabular}{|c|c|c|}
\hline The Primary Criteria & The Secondary Criteria & Definition of Significance \\
\hline \multirow{4}{*}{$\begin{array}{l}\text { The Physical Properties } \\
\text { (TS EN } 323 \text { 1999). }\end{array}$} & Density & $\begin{array}{l}\text { This property is significant for resistance } \\
\text { against mechanical influence. }\end{array}$ \\
\hline & Humidity ratio & $\begin{array}{l}\text { This property is significant for dimensional } \\
\text { stabilization and deterioration of material. }\end{array}$ \\
\hline & Thickness swelling & $\begin{array}{l}\text { This property is significant in the degradation } \\
\text { of the material. }\end{array}$ \\
\hline & Water absorption & $\begin{array}{l}\text { This property is significant in the degradation } \\
\text { of the material. }\end{array}$ \\
\hline \multirow{9}{*}{$\begin{array}{l}\text { The Mechanical } \\
\text { Properties; } \\
\text { (`TS EN } 12825 \text { 2003; } \\
\star \star * T S \text { EN } 4382006 \text {; } \\
\text { ***TS EN } 3112005)\end{array}$} & $\begin{array}{l}\text { Point load at the center } \\
\text { of the panel }\end{array}$ & $\begin{array}{l}\text { This property is significant for determining } \\
\text { the maximum point load-bearing property } \\
\text { at the center of the panel. }\end{array}$ \\
\hline & $\begin{array}{l}\text { Point load at the center } \\
\text { of the corner* }\end{array}$ & $\begin{array}{l}\text { This property is significant for determining } \\
\text { the point load-bearing property at the center } \\
\text { of the corner. }\end{array}$ \\
\hline & Distributed load ${ }^{*}$ & $\begin{array}{l}\text { This property is significant for determining } \\
\text { the maximum distributed load at panel. }\end{array}$ \\
\hline & Hard Body Impact $^{*}$ & \multirow{2}{*}{$\begin{array}{l}\text { This property is significant for determining } \\
\text { the panel surface. }\end{array}$} \\
\hline & Soft Body Impact* & \\
\hline & $\begin{array}{l}\text { Corner veneer bonding } \\
\text { strength }^{\star * \star} \\
\text { TS EN } 311-2005 \\
\end{array}$ & $\begin{array}{l}\text { This property is significant to protect the } \\
\text { edges of the material. }\end{array}$ \\
\hline & Scratching resistance ${ }^{\star *}$ & $\begin{array}{l}\text { This property is significant for the material } \\
\text { resistance against scratching effect. }\end{array}$ \\
\hline & Wear resistance ${ }^{\star *}$ & $\begin{array}{l}\text { This property is significant for the material } \\
\text { resistance against corrosive effects. }\end{array}$ \\
\hline & Cigarette fire resistance ${ }^{\star *}$ & $\begin{array}{l}\text { This property is significant to for the adverse } \\
\text { effects of smoking fire of the material surface. }\end{array}$ \\
\hline $\begin{array}{l}\text { The Safety Properties } \\
\text { (TS EN } 1081 \text { 1998) }\end{array}$ & $\begin{array}{l}\text { Electrical conduction } \\
\text { resistance }\end{array}$ & $\begin{array}{l}\text { This property is significant for determining } \\
\text { the conductivity - the insulation of the } \\
\text { material. }\end{array}$ \\
\hline $\begin{array}{l}\text { The Chemical } \\
\text { Properties } \\
\text { (TS EN } 438 \text { 2006) }\end{array}$ & $\begin{array}{l}\text { Stains formed by } \% 5 \\
\text { acetic acid, 5\% sulfuric } \\
\text { acid, 5\% hydrochloric } \\
\text { acid, 30\% hydrochloric } \\
\text { acid, sodium hydroxide, } \\
\text { ammonia, bleach, coffee, } \\
\text { tea, juice }\end{array}$ & $\begin{array}{l}\text { This property is significant for determining } \\
\text { the deterioration which chemicals are spilled } \\
\text { on the material surface. }\end{array}$ \\
\hline \multirow[b]{2}{*}{ The Cost } & Material price & $\begin{array}{l}\text { Material prices is significant for determining } \\
\text { the remuneration. }\end{array}$ \\
\hline & Labor costs & $\begin{array}{l}\text { Labor costs is significant for determining } \\
\text { the remuneration. }\end{array}$ \\
\hline
\end{tabular}


Table 5. The dual comparison matrix for the primary criteria

\begin{tabular}{|c|c|c|c|c|c|}
\hline Primary criteria & C1 & C2 & C3 & Weights (w) & $\lambda_{\max }$, CI, RI, CR \\
\hline C1 & 1 & 0.2 & 1 & 0.138 & $\lambda_{\max }=3.009$ \\
CI $=0.005$ \\
C2 & 5 & 1 & 6 & 0.732 & RI $=0.58$ \\
C3 & 1 & 0.17 & 1 & 0.130 & CR $=0.008$ \\
\hline
\end{tabular}

In this part, first of all, the team members form the fuzzy MOORA choice matrix inferred from Eq. (7) as given in Table 7.

The matrix contains the criteria values expressed with triangular fuzzy numbers and normalized by using Eq. (17), (18), (19). The normalized fuzzy choice matrix is shown in Table 8. A fuzzy weighted decision table is obtained upon the evaluation of fuzzy matrix in the second step, where the weighted evaluation matrix is also established with regard to Eq. (20), (21), (22) using the criteria weights calculated by AHP. The resultant of fuzzy weighted choice matrix is clearly illustrated in Table 9.

Table 6. Pair-wise comparison matrix of the secondary criteria

\begin{tabular}{|c|c|c|c|c|c|c|c|c|c|}
\hline $\begin{array}{c}\text { Secondary } \\
\text { criteria }\end{array}$ & SC3 & SC4 & SC5 & SC6 & SC7 & SC8 & SC9 & $\begin{array}{l}\text { Weights } \\
\text { (w) }\end{array}$ & $\lambda_{\max }, \mathrm{CI}, \mathrm{RI}, \mathrm{CR}$ \\
\hline SC1 & 1.0 & 1.0 & 1.0 & 5.0 & 3.0 & 3.0 & 9.0 & 0.255 & \multirow{7}{*}{$\begin{array}{l}\lambda \max =7.40 \\
\mathrm{CI}=0.068 \\
\mathrm{RI}=1.35 \\
\mathrm{CR}=0.050\end{array}$} \\
\hline SC2 & 1.0 & 1.0 & 1.0 & 3.0 & 3.0 & 3.0 & 7.0 & 0.222 & \\
\hline SC3 & 1.0 & 1.0 & 1.0 & 5.0 & 5.0 & 7.0 & 7.0 & 0.289 & \\
\hline SC4 & 0.2 & 0.3 & 0.2 & 1.0 & 4.0 & 1.0 & 1.0 & 0.078 & \\
\hline SC5 & 0.3 & 0.3 & 0.2 & 0.3 & 1.0 & 1.0 & 1.0 & 0.053 & \\
\hline SC6 & 0.3 & 0.3 & 0.1 & 1.0 & 1.0 & 1.0 & 1.0 & 0.059 & \\
\hline SC7 & 0.1 & 0.1 & 0.1 & 1.0 & 1.0 & 1.0 & 1.0 & 0.045 & \\
\hline
\end{tabular}

Table 7. Fuzzy panel selection decision matrix

\begin{tabular}{|c|c|c|c|c|c|c|}
\hline SC/M & $\mathrm{A}$ & $\mathrm{B}$ & $\mathrm{C}$ & $\mathrm{D}$ & $\mathrm{E}$ & $\mathrm{F}$ \\
\hline SC1 & $(0.67,0.87,1.00)$ & $(0.60,0.80,1.00)$ & $(0.60,0.80,1.00)$ & $(0.80,1.00,1.00)$ & $(0.73,0.93,1.00)$ & $(0.60,0.80,0.93)$ \\
\hline SC2 & $(0.00,0.07,0.27)$ & $(0.00,0.13,0.33)$ & $(0.33,0.53,0.73)$ & $(0.73,0.93,1.00)$ & $(0.73,0.93,1.00)$ & $(0.60,0.80,1.00)$ \\
\hline SC3 & $(0.67,0.87,1.00)$ & $(0.67,0.87,1.00)$ & $(0.67,0.87,1.00)$ & $(0.80,1.00,1.00)$ & $(0.67,0.87,1.00)$ & $(0.80,1.00,1.00)$ \\
\hline SC4 & $(0.67,0.87,1.00)$ & $(0.67,0.87,1.00)$ & $(0.67,0.87,1.00)$ & $(0.73,0.93,1.00)$ & $(0.73,0.93,1.00)$ & $(0.73,0.93,1.00)$ \\
\hline SC5 & $(0.73,0.93,1.00)$ & $(0.60,0.80,0.93)$ & $(0.60,0.80,0.93)$ & $(0.73,0.93,1.00)$ & $(0.73,0.93,1.00)$ & $(0.80,1.00,1.00)$ \\
\hline SC6 & $(0.33,0.53,0.73)$ & $(0.20,0.33,0.53)$ & $(0.40,0.60,0.80)$ & $(0.80,1.00,1.00)$ & $(0.60,0.80,0.93)$ & $(0.73,0.93,1.00)$ \\
\hline SC7 & $(0.27,0.47,0.67)$ & $(0.53,0.73,0.93)$ & $(0.53,0.73,0.93)$ & $(0.67,0.87,1.00)$ & $(0.80,1.00,1.00)$ & $(0.67,0.87,1.00)$ \\
\hline SC8 & $(0.60,0.80,1.00)$ & $(0.60,0.80,0.93)$ & $(0.27,0.47,0.67)$ & $(0.80,1.00,1.00)$ & $(0.80,1.00,1.00)$ & $(0.73,0.93,1.00)$ \\
\hline SC9 & $(0.07,0.13,0.33)$ & $(0.67,0.87,0.93)$ & $(0.67,0.87,1.00)$ & $(0.67,0.87,0.93)$ & $(0.73,0.93,1.00)$ & $(0.73,0.93,1.00)$ \\
\hline SC10 & $(0.67,0.87,1.00)$ & $(0.67,0.87,1.00)$ & $(0.80,1.00,1.00)$ & $(0.00,0.07,0.27)$ & $(0.00,0.20,0.40)$ & $(0.27,0.47,0.60)$ \\
\hline
\end{tabular}


Table 8. Normalized fuzzy decision matrix

\begin{tabular}{|c|c|c|c|c|c|c|}
\hline SC/M & $\mathrm{A}$ & $\mathrm{B}$ & $\mathrm{C}$ & $\mathrm{D}$ & $\mathrm{E}$ & $\mathrm{F}$ \\
\hline SC1 & $(0.406,0.527,0.608)$ & $(0.365,0.487,0.608)$ & $(0.365,0.487,0.608)$ & $(0.487,0.608,0.608)$ & $(0.446,0.568,0.608)$ & $(0.365,0.487,0.568)$ \\
\hline SC2 & $(0.000,0.041,0.162)$ & $(0.000,0.081,0.203)$ & $(0.203,0.324,0.446)$ & $(0.446,0.568,0.608)$ & $(0.446,0.568,0.608)$ & $(0.365,0.487,0.608)$ \\
\hline SC3 & $(0.406,0.527,0.608)$ & $(0.406,0.527,0.608)$ & $(0.406,0.527,0.608)$ & $(0.487,0.608,0.608)$ & $(0.406,0.527,0.608)$ & $(0.487,0.608,0.608)$ \\
\hline SC4 & $(0.406,0.527,0.608)$ & $(0.406,0.527,0.608)$ & $(0.406,0.527,0.608)$ & $(0.446,0.568,0.608)$ & $(0.446,0.568,0.608)$ & $(0.446,0.568,0.608)$ \\
\hline SC5 & $(0.446,0.568,0.608)$ & $(0.365,0.487,0.568)$ & $(0.365,0.487,0.568)$ & $(0.446,0.568,0.608)$ & $(0.446,0.568,0.608)$ & $(0.487,0.608,0.608)$ \\
\hline SC6 & $(0.203,0.324,0.446)$ & $(0.122,0.203,0.324)$ & $(0.243,0.365,0.487)$ & $(0.487,0.608,0.608)$ & $(0.365,0.487,0.568)$ & $(0.446,0.568,0.608)$ \\
\hline SC7 & $(0.162,0.284,0.406)$ & $(0.324,0.446,0.568)$ & $(0.324,0.446,0.568)$ & $(0.406,0.527,0.608)$ & $(0.487,0.608,0.608)$ & $(0.406,0.527,0.608)$ \\
\hline SC8 & $(0.365,0.487,0.608)$ & $(0.365,0.487,0.568)$ & $(0.162,0.284,0.406)$ & $(0.487,0.608,0.608)$ & $(0.487,0.608,0.608)$ & $(0.446,0.568,0.608)$ \\
\hline SC9 & $(0.041,0.081,0.203)$ & $(0.406,0.527,0.568)$ & $(0.406,0.527,0.608)$ & $(0.406,0.527,0.568)$ & $(0.446,0.568,0.608)$ & $(0.446,0.568,0.608)$ \\
\hline SC10 & $(0.406,0.527,0.608)$ & $(0.406,0.527,0.608)$ & $(0.487,0.608,0.608)$ & $(0.000,0.041,0.162)$ & $(0.000,0.122,0.243)$ & $(0.162,0.284,0.365)$ \\
\hline
\end{tabular}

Table 9. Weighted normalized fuzzy decision matrix

\begin{tabular}{|c|c|c|c|c|c|c|}
\hline SC/M & $\mathrm{A}$ & $\mathrm{B}$ & $\mathrm{C}$ & $\mathrm{D}$ & $\mathrm{E}$ & $\mathrm{F}$ \\
\hline SC1 & $(0.028,0.036,0.042)$ & $(0.025,0.034,0.042)$ & $(0.025,0.034,0.042)$ & $(0.034,0.042,0.042)$ & $(0.031,0.039,0.042)$ & $(0.025,0.034,0.039)$ \\
\hline SC2 & $(0.000,0.003,0.011)$ & $(0.000,0.006,0.014)$ & $(0.014,0.022,0.031)$ & $(0.031,0.039,0.042)$ & $(0.031,0.039,0.042)$ & $(0.025,0.034,0.042)$ \\
\hline SC3 & $(0.076,0.099,0.114)$ & $(0.076,0.099,0.114)$ & $(0.076,0.099,0.114)$ & $(0.091,0.114,0.114)$ & $(0.076,0.099,0.114)$ & $(0.091,0.114,0.114)$ \\
\hline SC4 & $(0.065,0.085,0.098)$ & $(0.065,0.085,0.098)$ & $(0.065,0.085,0.098)$ & $(0.072,0.091,0.098)$ & $(0.072,0.091,0.098)$ & $(0.072,0.091,0.098)$ \\
\hline SC5 & $(0.095,0.120,0.129)$ & $(0.077,0.103,0.120)$ & $(0.077,0.103,0.120)$ & $(0.095,0.120,0.129)$ & $(0.095,0.120,0.129)$ & $(0.103,0.129,0.129)$ \\
\hline SC6 & $(0.012,0.018,0.025)$ & $(0.007,0.012,0.018)$ & $(0.014,0.021,0.028)$ & $(0.028,0.035,0.035)$ & $(0.021,0.028,0.032)$ & $(0.025,0.032,0.035)$ \\
\hline SC7 & $(0.006,0.011,0.016)$ & $(0.013,0.017,0.022)$ & $(0.013,0.017,0.022)$ & $(0.016,0.021,0.024)$ & $(0.019,0.024,0.024)$ & $(0.016,0.021,0.024)$ \\
\hline SC8 & $(0.016,0.021,0.026)$ & $(0.016,0.021,0.024)$ & $(0.007,0.012,0.017)$ & $(0.021,0.026,0.026)$ & $(0.021,0.026,0.026)$ & $(0.019,0.024,0.026)$ \\
\hline SC9 & $(0.001,0.003,0.007)$ & $(0.013,0.017,0.019)$ & $(0.013,0.017,0.020)$ & $(0.013,0.017,0.019)$ & $(0.015,0.019,0.020)$ & $(0.015,0.019,0.020)$ \\
\hline SC10 & $(0.053,0.069,0.079)$ & $(0.053,0.069,0.079)$ & $(0.063,0.079,0.079)$ & $(0.000,0.005,0.021)$ & $(0.000,0.016,0.032)$ & $(0.021,0.037,0.047)$ \\
\hline
\end{tabular}

Among ten selection criteria given in Table 9, the thickness swelling (SC2), point load at the centre of the panel (SC3), point load at the centre of the corner (SC4), distributed load (SC5), electrical conduction resistance (SC9) and material price (SC10) should be captured in the lower values whereas the values belonging to the density (SC1), corner veneer bonding strength (SC6), scratching resistance (SC7), and wear resistance (SC8) should be higher due to the inherit beneficial features for the materials we can form throughout Table 10. Namely, the whole scores of useful criteria for the considered alternatives are calculated using the third step Eq. (23), (24), (25). Similarly, the whole ratings of non-useful criteria for the alternatives are calculated by applying Eq. (26), (27), (28). The whole scores for both useful and non-useful criteria are defined for the six alternative raised floor panels. Now, the vertex method is used to simplify the whole scores for useful and non-useful criteria to reproduce the whole performance shown for all the panel alternatives. The performance index calculation is provided as an example as follows (Eq. (29)):

$$
\begin{aligned}
& S_{i}^{+l}=0.028+0.012+0.006+0.016=0.062 \\
& S_{j}=0.000+0.076+0.065+0.095+0.001+0.053=0.290 ; \\
& S_{i}=\left(s_{i}^{+}, s_{i}^{-}\right)=\sqrt{\frac{1}{3}(0062-0290)^{2}+(0087-0378)^{2}+(0109-0438)^{2}}=0.285 .
\end{aligned}
$$


Table 10. Performance score ranks of alternative panels

\begin{tabular}{|c|c|c|c|c|c|c|c|c|}
\hline $\mathrm{M} / \mathrm{S}$ & \multicolumn{3}{|c|}{$\mathrm{S}^{+}$} & \multicolumn{3}{c|}{$\mathrm{S}^{-}$} & Rank \\
\hline $\mathrm{A}$ & 0.062 & 0.087 & 0.109 & 0.290 & 0.378 & 0.438 & 0.285 & 4 \\
\hline $\mathrm{B}$ & 0.060 & 0.083 & 0.107 & 0.285 & 0.378 & 0.444 & 0.289 & 3 \\
\hline $\mathrm{C}$ & 0.059 & 0.084 & 0.109 & 0.309 & 0.406 & 0.462 & 0.311 & 1 \\
\hline $\mathrm{D}$ & 0.098 & 0.123 & 0.127 & 0.302 & 0.387 & 0.422 & 0.257 & 6 \\
\hline E & 0.091 & 0.117 & 0.124 & 0.288 & 0.384 & 0.434 & 0.262 & 5 \\
\hline F & 0.086 & 0.111 & 0.124 & 0.327 & 0.423 & 0.450 & 0.296 & 2 \\
\hline
\end{tabular}

Similar computations are conducted for the added panel alternatives and the outcomes of fuzzy MOORA evaluates are numerically summarized in Table 10. Depending on the index worth determined, the ordering of the panel alternatives is composed of the falling rank as C, F, B, A, E and D, respectively. Planned exemplary results demonstrate that the panel abbreviated as $\mathrm{C}$ with index value of 0.311 is noticed to be the best alternative.

\section{Conclusions}

The selection of materials for decoration is a difficult process performed by purchasing departments of companies. Different materials manufactured by companies may exhibit similar properties. However, every company claims with respect to own catalogue information that they fabricate higher quality materials compare others. It is the duty of personnel working in the purchasing departments to resolve the confusion within the correct decision. Even, the personnel employed in the company should consider all the criteria with clear viewpoint. Accordingly, companies generally make selections by placing only the cost criteria in the forefront for their own self-interests. However, it is noticed in time that decisions made in this manner are not right because of unsatisfied final customers. A choice exemplary is ensured for raised floor panel choice practice in the present study. The planned model depends on analyzes of different panels in terms of the criteria identified. The AHP and fuzzy MOORA methods are used in an integrated manner along with the model proposed. The criteria values are inferred in an objective manner within laboratory environment. The material selection in construction industry according to the model achieved has not been studied in the literature until now. Additionally, the AHP method enables us to form higher weight values that distinguishes as an important criterion. The raised floor panels are listed in order by calculating the fuzzy normalized and fuzzy weighted values of the ideal index value with the MOORA method. Thus, the selection of ideal material is realized most properly. In this respect, multiple choice-makers are constantly considered better than a single choice-maker to forestall prejudice and minimize favoritism in the choice practice. Likewise, it is almost impossible for a single decision-maker to correctly evaluate many factors alone. Namely, the model proposed clearly facilitates the work of employees in purchasing departments and in fact decrease the work load. What stands out clearly here is that the model being able to evaluate many criteria instantly is implemented in a successful method for the problem of the raised floor panel selection. In short, this model including the management of expert and 
intelligent systems could be used in the applications of construction industry materials as a consequence of the improvement in criteria. To sum up, the analysis of development and management of the systems along with bidding process may open up a novel and feasible area for the engineering and industry applications.

\section{References}

Akhavan, P.; Barak, S.; Maghsoudlou, S.; Antuchevičienè, J. 2015. FQSPM-SWOT for strategic alliance planning and partner selection; case study in a holding car manufacturer company, Technological and Economic Development of Economy 21(2): 165-185. https://doi.org/10.3846/20294913.2014.965240

Akkaya, G.; Turanoğlu, B.; Öztaş, S. 2015. An integrated fuzzy AHP and fuzzy MOORA approach to the problem of industrial engineering sector choosing, Expert Systems with Applications 42(24): 9565-9573. https://doi.org/10.1016/j.eswa.2015.07.061

Arbel, A.; Orgler, Y. E. 1990. An application of the AHP to bank strategic planning: the mergers and acquisitions process, European Journal of Operational Research 48(1): 27-37. https://doi.org/10.1016/0377-2217(90)90058-J

Archana, M.; Sujatha, V. 2012. Application of fuzzy MOORA and GRA in multi criterion decision making problems, International Journal of Computer Applications 53(9): 46-50. https://doi.org/10.5120/8452-2249

Balezentis, T. 2011. A farming efficiency estimation model based on fuzzy Multimoora, Management Theory and Studies for Rural Business and Infrastructure Development 5(29): 43-52.

Balezentis, A.; Balezentis, T.; Brauers, W. K. M. 2012. Multimoora-FG: a multi-objective decision making method for linguistic reasoning with an application to personnel selection, Informatica 23(2): 173-190.

Brauers, W. K. 2004. Optimization methods for a stakeholder society: a revolution in economic thinking by multi-objective optimization. Boston: Kluwer Academic Publishers. https://doi.org/10.1007/978-1-4419-9178-2

Brauers, W. K. M.; Zavadskas, E. K. 2006. The MOORA method and its application to privatization in a transition economy, Control and Cybernetics 35(2): 445-469.

Brauers, W. K. M.; Zavadskas, E. K. 2012. Robustness of MULTIMOORA: a method for multi- objective optimization, Informatica 23(1): 1-25.

Chakraborty, S. 2010. Application of the MOORA method for decision making in manufacturing environment, International Journal of Advanced Manufacturing Technology 54(9): 1155-1166.

Chang, S. C.; Tsai, P. H. 2016. A hybrid financial performance evaluation model for wealth management banks following the global financial crisis, Technological and Economic Development of Economy 22(1): 21-46. https://doi.org/10.3846/20294913.2014.986771

Chang, Y. H.; Yeh, C. H. 2002. A survey analysis of service quality for domestic airlines, European Journal of Operational Research 139(1): 166-177. https://doi.org/10.1016/S0377-2217(01)00148-5

Chang, Y. H.; Yeh, C. H.; Wang, S. Y. 2007. A survey and optimization-based evaluation of development strategies for the air cargo industry, International Journal of Production Economics 106(2): 550-562. https://doi.org/10.1016/j.ijpe.2006.06.016

Chen, C. T. 2000. Extensions of the TOPSIS for group decision-making under fuzzy environment, Fuzzy Sets and Systems 114(1): 1-9. https://doi.org/10.1016/S0165-0114(97)00377-1

Chen, C. T.; Lin, C. T.; Huang, S. F. 2006. A fuzzy approach for supplier evaluation and selection in supply chain management, International Journal of Production Economics 102(2): 289-301. https://doi.org/10.1016/j.ijpe.2005.03.009 
Cheng, C. H. 1997. Evaluating naval tactical missile systems by fuzzy AHP based on the grade value of membership function, European Journal of Operational Research 96(2): 343-350. https://doi.org/10.1016/S0377-2217(96)00026-4

Dağdeviren, M.; Eren, T. 2001. Analytical hierarchy process and use of 0-1 goal programming methods in selecting supplier firm, Journal of the Faculty of Engineering and Architecture of Gazi University 16(2): 41-52 (In Turkish).

Dağdeviren, M.; Yavuz, S.; Kılınç, N. 2009. Weapon selection using the AHP and TOPSIS methods under fuzzy environment, Expert Systems with Applications 36(4): 8143-8151. https://doi.org/10.1016/j.eswa.2008.10.016

Dey, B.; Bairagi, B.; Sarkar, B.; Sanyal, S. 2012. A MOORA based fuzzy multi criteria decision making approach for supply chain strategy selection, International Journal of Industrial Engineering Computations 3(4): 649-662. https://doi.org/10.5267/j.ijiec.2012.03.001

Deng, X.; Hu, Y.; Deng, Y.; Mahadevan, S. 2014. Supplier selection using AHP methodology extended by D numbers, Expert Systems with Applications 41(1): 156-167. https://doi.org/10.1016/j.eswa.2013.07.018

Ding, J. F.; Liang, G. S. 2005. Using fuzzy MCDM to select partners of strategic alliances for liner shipping, Information Sciences 173(1-3): 197-225. https://doi.org/10.1016/j.ins.2004.07.013

Douligeris, C.; Pereira I. J. 1994. A telecommunications quality study using the analytic hierarchy process, IEEE Journal on Selected Areas in Communications 12(2): 241-250. https://doi.org/10.1109/49.272873

Ecer, F. 2014. A hybrid banking websites quality evaluation model using AHP and COPRAS-G: a Turkey case, Technological and Economic Development of Economy 20(4): 758-782. https://doi.org/10.3846/20294913.2014.915596

Ghodsypour, S. H.; Brien, C. O. 1998. A decision support system for supplier selection using an integrated analytic hierarchy process and linear programming, International Journal of Production Economics 56-57: 199-212. https://doi.org/10.1016/S0925-5273(97)00009-1

Ho, W. 2008. Integrated analytic hierarchy process and its applications - a literature review, European Journal of Operational Research 186(1): 211-228. https://doi.org/10.1016/j.ejor.2007.01.004

Ho, W.; Xu, X.; Dey, P. K. 2010. Multi-criteria decision making approaches for supplier evaluation and selection: a literature review, European Journal of Operational Research 202(1): 16-24. https://doi.org/10.1016/j.ejor.2009.05.009

Ilce, A.C. 2007. Investigation of physical mechanical properties of raised flooring materials used in computerized spaces, and determination of their effects on space design: $\mathrm{PhD}$ thesis. Hacettepe University (In Turkish).

Kahraman, C.; Cebeci, U.; Ulukan, Z. 2003. Multi-criteria supplier selection using fuzzy AHP, Logistics Information Management 16(6): 382-394. https://doi.org/10.1108/09576050310503367

Kahraman, C.; Beskese, A.; Ruan, D. 2004. Measuring flexibility of computer integrated manufacturing systems using fuzzy cash flow analysis, Information Sciences 168(1-4): 77-94. https://doi.org/10.1016/j.ins.2003.11.004

Karsak, E. E.; Tolga, E. 2001. Fuzzy multi-criteria decision-making procedure for evaluating advanced manufacturing system investments, International Journal of Production Economics 69(1): 49-64. https://doi.org/10.1016/S0925-5273(00)00081-5

Karande, P.; Chakraborty, S. 2012. A fuzzy-MOORA approach for ERP system selection, Decision Science Letters 1(1): 11-21. https://doi.org/10.5267/j.dsl.2012.07.001

Kaya, T., Kahraman, C. 2011. A fuzzy approach to e-bankıng website quality assessment based on an integrated AHP-ELECTRE method, Technological and Economic Development of Economy 17(2): 313-334. https://doi.org/10.3846/20294913.2011.583727 
Lai, V. S.; Trueblood, R. P.; Wong, B. K. 1999. Software selection: a case study of the application of the analytical hierarchical process to the selection of a multimedia authoring system, Information \& Management 36(4): 221-232. https://doi.org/10.1016/S0378-7206(99)00021-X

Mandal, U. K.; Sarkar, B. 2012. Selection of best intelligent manufacturing system under fuzzy MOORA conflicting MCDM environment, International Journal of Engineering Technology and Advanced Engineering 2(9): 301-310.

Mansor, M. R.; Sapuan, S. M.; Zainudin, E. S.; Nuraini, A. A.; Hambali, A. 2013. Hybrid natural and glass fibers reinforced polymer composites material selection using Analytical Hierarchy Process for automotive brake lever design, Materials and Design 51: 484-492.

https://doi.org/10.1016/j.matdes.2013.04.072

Oztaysi, B. 2014. A decision model for information technology selection using AHP integrated TOPSISGrey: the case of content management systems, Knowledge-Based Systems 70(C): 44-54. https://doi.org/10.1016/j.knosys.2014.02.010

Önüt, S.; Soner, S. 2008. Transshipment site selection using the AHP and TOPSIS approaches under fuzzy environment, Waste Management 28(9): 1552-1559.

https://doi.org/10.1016/j.wasman.2007.05.019

Pourahmad, A.; Hosseini, A.; Banaitis, A.; Nasiri, H.; Banaitienė, N.; Tzeng, G. H. 2015. Combination of FUZZY-AHP and DEMANTEL-ANP with gis in a new hybrid MCDM model used for the selection of the best space for leisure in a blighted urban site, Technological and Economic Development of Economy 21(5): 773-796. https://doi.org/10.3846/20294913.2015.1056279

Raj, P. A.; Kumar, D. N. 1999. Ranking alternatives with fuzzy weights using maximizing set and minimizing set, Fuzzy Sets and Systems 105(3): 365-375. https://doi.org/10.1016/S0165-0114(97)00243-1

Saaty, T. L. 1990. How to make a decision: the analytic hierarchy process, European Journal of Operational Research 48(1): 9-26. https://doi.org/10.1016/0377-2217(90)90057-I

Saaty, T. L. 2008. Decision making with the analytic hierarchy process, International Journal of Services Sciences 1(1): 83-98. https://doi.org/10.1504/IJSSCI.2008.017590

Sivakumar, R.; Kannan, D.; Murugesan, P. 2015. Green vendor evaluation and selection using AHP and Taguchi loss functions in production outsourcing in mining industry, Resources Policy 46(1): 64-75. https://doi.org/10.1016/j.resourpol.2014.03.008

Stanujkic, D. 2013. An extension of the MOORA method for solving fuzzy decision making problems, Technological and Economic Development of Economy 19(1): 228-255. https://doi.org/10.3846/20294913.2013.880083

Tam, M. C. Y.; Tummala, V. M. R. 2001. An application of the AHP in vendor selection of a telecommunications system, OMEGA 29(2): 171-182. https://doi.org/10.1016/S0305-0483(00)00039-6

TS EN 323:1999. Wood- Based panels- Determination of Density. Turkish Standard. (In Turkish).

TS EN 12825:2003. Raised access floors. Turkish Standard. (In Turkish).

TS EN 438:2006. High-pressure decorative laminates (HPL) - Sheets based on thermosetting resins (Usually called laminates) - Part 1: Introduction and general information. Turkish Standard. (In Turkish).

TS EN 311:2005. Wood-based panels - Surface soundness - Test method. Turkish Standard. (In Turkish).

TS EN 1081:1998. Resilient floorcoverings-Determination of the electrical resistance. Turkish Standard. (In Turkish).

Uyan, M. 2013. GIS-based solar farms site selection using analytic hierarchy process (AHP) in Karapinar region, Konya/Turkey, Renewable and Sustainable Energy Reviews 28: 11-17.

https://doi.org/10.1016/j.rser.2013.07.042

Vargas, L. G. 1990. An overview of the AHP and its application, European Journal of Operational Research 48(1): 2-8. https://doi.org/10.1016/0377-2217(90)90056-H 
Vatansever, K.; Kazançoğlu, Y. 2014. Integrated usage of fuzzy multi criteria decision making techniques for machine selection problems and an application, International Journal of Business and Social Science 5(9): 12-24.

Wang, T. C.; Chang, T. H. 2007. Application of TOPSIS in evaluating initial training aircraft under a fuzzy environment, Expert Systems with Applications 33(4): 870-880. https://doi.org/10.1016/j.eswa.2006.07.003

Wang, X.; Chan, H. K.; Lee, C. K. M.; Li, D. 2015. A hierarchical model for eco-design of consumer electronic products, Technological and Economic Development of Economy 21(1): 48-64. https://doi.org/10.3846/20294913.2013.876685

Xu, L.; Kumar, D. T.; Shankar, K. M.; Kannan, D.; Chen, G. 2013. Analyzing criteria and sub-criteria for the corporate social responsibility-based supplier selection process using AHP, The International Journal of Advanced Manufacturing Technology 68: 907-916. https://doi.org/10.1007/s00170-013-4952-7

Xu, Z. S.; Chen, J. 2007. An interactive method for fuzzy multiple attribute group decision making, Information Sciences 177(1): 248-263. https://doi.org/10.1016/j.ins.2006.03.001

Zadeh, L. A. 1965. Fuzzy sets, Information and Control 8(3): 338-353. https://doi.org/10.1016/S0019-9958(65)90241-X

Zadeh, L. A. 1975. The concept of a linguistic variable and its application to approximate reasoning I, Information Sciences 8: 199-249. https://doi.org/10.1016/0020-0255(75)90036-5

Zahedi, F. 1987. A Utility approach to the AHP, Mathematical Modelling 9(3-5): 387-395. https://doi.org/10.1016/0270-0255(87)90497-0

Zimmerman, H. J. 1996. Fuzzy sets theory and its applications. Boston: Kluwer Academic Publishers. https://doi.org/10.1007/978-94-015-8702-0

Zolfani, S. H.; Chen, I. S.; Rezaeiniya, N.; Tamošaitiené, J. 2012. A hybrid MCDM model encompassing AHP and COPRAS-G methods for selecting company supplier in Iran, Technological and Economic Development of Economy 18(3): 529-543. https://doi.org/10.3846/20294913.2012.709472

Zviran, M. A. 1993. Comprehensive methodology for computer family selection, Journal Systems Software 22(1): 17-26. https://doi.org/10.1016/0164-1212(93)90119-I 